\title{
Effect of Slag Melting Behavior on Metal-Slag Separation Temperature in Powdery Iron, Slag and Carbon Mixture
}

\author{
Ko-ichiro OHNO, ${ }^{1)}$ Masashi KAIMOTO, ${ }^{2)}$ Takayuki MAEDA, ${ }^{11}$ Koki NISHIOKA ${ }^{1)}$ and Masakata SHIMIZU ${ }^{11}$ \\ 1) Department of Materials Science and Engineering, Faculty of Engineering, Kyushu University, Motooka 744, Nishi-ku,

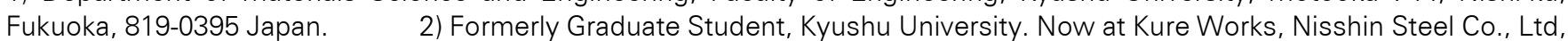 \\ Showa-cho 11-1, Kure-shi, Hiroshima, 737-8520 Japan.
}

(Received on January 20, 2011; accepted on March 1, 2011)

\begin{abstract}
Utilization of self reducing pellet in blast furnace is one of the effective technologies to mitigate the $\mathrm{CO}_{2}$ emissions in the steel industry. However, there are not sufficient researches on how the pellet behaves around cohesive zone. Therefore, purpose of this study is to clarify the effect of slag melting behavior on metal-slag separation behavior. In order to simulate the behavior around cohesive zone, electrolytic iron powder, carbon powder, and synthetic slag were prepared as reduced iron, residual carbon and slag components, respectively. They were well mixed as given mass ratios decided from the composition of the self reducing pellet. Different kinds of slag compositions were adopted to change properties, such as melting temperature and viscosity. The mixtures were pressed into tablets and used as experimental samples. "In-situ" observations of metal-slag separation behavior in the mixtures during constant rate heating were done by a laser microscope combined with infra-red furnace and metal-slag separation temperatures were decided. Following results were obtained. The metal-slag separation behavior was dominated largely by agglomeration behavior of liquid phase of iron. The separation surely occurred when both phases of iron and slag change to liquid phases. At the same time, the separation could also occur even if a small amount of solid phases still remained in the mixture. In this experimental condition, the effect of slag melting temperature on the separation was larger than the effect of slag's viscosity.
\end{abstract}

KEY WORDS: slag melting temperature; viscosity of slag; metal-slag separation behavior; agglomeration behavior of $\mathrm{Fe}-\mathrm{C}$ liquid; laser microscope; "in-situ" observation.

\section{Introduction}

Utilization of self reducing pellet in blast furnace is one of the effective technologies to mitigate the $\mathrm{CO}_{2}$ emissions in the steel industry. In the self reducing pellet, an average distance between iron ores and coals is really closer than the distance charged by conventional layer-by-layer method. This proximity of ore to coal in the pellet derives a coupling reaction ${ }^{1)}$ and a reduction of mass transfer resistance, then reaction rate is enhanced. This approach is focused as one of the expectant technologies to make thermal reserve zone temperature lower in a blast furnace. It has been reported that about $200 \mathrm{~K}$ of the thermal reserve zone temperature decrease was confirmed by an experiment using the self reducing pellet in the adiabatic blast furnace simulator. ${ }^{2)}$ However, there are not sufficient researches on how the pellets soften and melt around the cohesive zone. In this region, smooth separation of slag and metal is especially important and carburization reaction could be one of the main factors to control this behavior.

It has been generally considered that the carburization reaction in cohesive zone occurred by direct contact between reduced irons and cokes or by carbonaceous gas. From kinetic comparison between them, several studies reported the carburization by direct contact in solid state is dominant in this zone., ${ }^{3,4)}$ At the same time, it was reported that the slag melting behavior has strong effect on the direct contact carburization reaction by several researchers. ${ }^{5-10)}$ In this study, the slag melting behavior means minerals in iron ore and ash in cokes change from solid phase to liquid phase. Matsui et al. ${ }^{6}$ ) reported the effect of minerals of iron ore on carburization behavior. Heru et al. ${ }^{7)}$ and Chapman et $a l .{ }^{8)}$ mentioned the effect of ash on carburization behavior. Both of studies indicated that easy melting of mineral and ash has an advantage for the carburization reaction. However, there are not sufficient studies focused on a separation behavior of metal and slag during carburization reaction.

Therefore, purpose of this study is to clarify the effect of slag melting behavior on metal-slag separation behavior by in-situ observation method with a confocal laser-scanning microscope.

\section{Experiment}

In the present work, microscopic "in-situ" observation of metal-slag separation behavior during heating experiment carried out to make the object clear. A confocal laser-scanning microscope combined with an infra-red image-heating furnace, ${ }^{11)}$ which enables us to make microscopic "in-situ" observation at high temperature, was used in the present work. 


\subsection{Samples}

In order to simulate the state of self reducing pellet around cohesive zone, electrolytic iron powder, carbon powder, and synthetic slag were prepared as reduced iron, residual carbon, and slag components, respectively. They were well mixed as given mass ratios decided from the composition of the self reducing pellet as shown in Table 1.

The mixing ratios of these powders were decided on the basis of following ideas; 4 kinds of carbon mixing ratios to iron powder were applied as 1, 2, 3 or 4 mass $\%$. The slag mixing ratio to iron powder was basically fixed as 13.1 mass $\%$. This value of slag mixing ratio was derived from the amounts of mineral included in the ore and ash included in the coal when practical self reducing pellet ${ }^{12)}$ made from mixture of Romeral ore and Jellimbar coal was used.

Table 1. Basic mixing ratio between Fe powder, carbon powder and synthesis slag for experimental tablet samples making.

\begin{tabular}{|c|c|c|c|c|}
\hline \multicolumn{3}{|c|}{ Sample mixing ratio (mass $\%$ ) } & \multirow{2}{*}{$\begin{array}{l}\text { Carbon mixing } \\
\text { ratio to } \mathrm{Fe} \\
\text { (mass } \%)\end{array}$} & \multirow{2}{*}{$\begin{array}{c}\text { Slag mixing } \\
\text { ratio to } \mathrm{Fe} \\
(\operatorname{mass} \%)\end{array}$} \\
\hline $\begin{array}{c}\mathrm{Fe} \\
\text { powder }\end{array}$ & $\begin{array}{l}\text { Carbon } \\
\text { powder }\end{array}$ & $\begin{array}{c}\text { Synthesis } \\
\text { slag }\end{array}$ & & \\
\hline 87.6 & 0.9 & 11.5 & 1.0 & 13.1 \\
\hline 86.8 & 1.8 & 11.4 & 2.0 & 13.1 \\
\hline 86.0 & 2.7 & 11.3 & 3.0 & 13.1 \\
\hline 85.2 & 3.6 & 11.2 & 4.0 & 13.1 \\
\hline
\end{tabular}

Table 2. Mixing ratio of experimental tablet samples for investigation about effect of amount of slag on the meta-slag separation behavior.

\begin{tabular}{|c|c|c|c|c|}
\hline \multicolumn{3}{|c|}{ Sample mixing ratio (mass $\%$ ) } & \multirow{2}{*}{$\begin{array}{l}\text { Carbon mixing } \\
\text { ratio to } \mathrm{Fe} \\
(\operatorname{mass} \%)\end{array}$} & \multirow{2}{*}{$\begin{array}{l}\text { Slag mixing } \\
\text { ratio to } \mathrm{Fe} \\
\text { (mass } \%)\end{array}$} \\
\hline $\begin{array}{c}\mathrm{Fe} \\
\text { powder }\end{array}$ & $\begin{array}{l}\text { Carbon } \\
\text { powder }\end{array}$ & $\begin{array}{c}\text { Synthesis } \\
\text { slag }\end{array}$ & & \\
\hline 85.2 & 3.6 & 11.2 & 4.0 & 13.1 \\
\hline 91.0 & 3.8 & 5.9 & 4.0 & 6.55 \\
\hline 76.7 & 3.2 & 20.1 & 4.0 & 26.2 \\
\hline
\end{tabular}

Table 3. Compositions of experimental slags which have different melting behavior.

\begin{tabular}{lcccccc}
\hline & \multicolumn{5}{c}{ Content (mass\%) } & $\begin{array}{c}\text { Melting } \\
\text { Sample }\end{array}$ \\
\cline { 2 - 6 } & $\mathrm{Al}_{2} \mathrm{O}_{3}$ & $\mathrm{CaO}$ & $\mathrm{SiO}_{2}$ & $\mathrm{Li}_{2} \mathrm{O}$ & $\mathrm{CaO} / \mathrm{SiO}_{2}$ & $(\mathrm{~K})$ \\
\hline Slag A & 20.5 & 37.9 & 41.6 & 0 & 0.91 & 1568 \\
Slag B & 30.0 & 36.8 & 33.3 & 0 & 1.17 & 1748 \\
Slag A5 & 19.5 & 36.0 & 39.5 & 5.0 & 0.91 & 1433 \\
Slag A10 & 18.5 & 34.1 & 37.4 & 10.0 & 0.91 & 1383 \\
\hline
\end{tabular}

Table 4. Compositions of experimental slags which have obviously different viscosity.

\begin{tabular}{|c|c|c|c|c|c|c|}
\hline \multirow{2}{*}{ Sample } & \multicolumn{4}{|c|}{ Content (mass $\%$ ) } & \multirow{2}{*}{$\begin{array}{c}\text { Melting } \\
\text { point } \\
(\mathrm{K})\end{array}$} & \multirow{2}{*}{$\begin{array}{c}\text { Viscosity at } \\
1673 \mathrm{~K} \\
\text { (poise) }\end{array}$} \\
\hline & $\mathrm{Al}_{2} \mathrm{O}_{3}$ & $\mathrm{CaO}$ & $\mathrm{SiO}_{2}$ & $\mathrm{CaO} / \mathrm{SiO}_{2}$ & & \\
\hline Slag C & 21.0 & 25.6 & 53.4 & 0.48 & 1673 & 125 \\
\hline Slag D & 21.0 & 22.1 & 56.9 & 0.39 & 1673 & 300 \\
\hline
\end{tabular}

Additionally in this study, in order to investigate an effect of amount of slag in the mixtures, we prepared other mixtures which contain half and twice mixing ratios of slag compared to the basic mixture as shown in Table 2.

Grain size of the iron powder was $-150 \mu \mathrm{m}$ and the purity was $99.9 \%$. The size of carbon powder was $25-32 \mu \mathrm{m}$ and the purity was $99.99 \%$. The synthetic slag powder was prepared as the same size as the size of carbon $(25-32 \mu \mathrm{m})$ by crushing and sieving treatment. The mixtures were pressed into tablets of $5 \mathrm{~mm}$ in the diameter using dies.

6 kinds of slags were prepared by melting and quenching the mixtures of reagent grade oxide powders as shown in Tables 3 and 4. Slag A and B were designed and were based on a typical slag component in a blast furnace as shown in a ternary phase diagram of $\mathrm{CaO}-\mathrm{SiO}_{2}-\mathrm{Al}_{2} \mathrm{O}_{3}$ as Fig. 1. ${ }^{13)}$ As the slags, which show relatively lower melting temperatures, Slag $\mathrm{A}+\mathrm{Li}_{2} \mathrm{O} 5$ mass $\%$ and 10 mass $\%$ were prepared by adding $\mathrm{Li}_{2} \mathrm{O}$ to Slag $\mathrm{A}$. Hereinafter, Slag $\mathrm{A}+\mathrm{Li}_{2} \mathrm{O} 5$ mass $\%$ and Slag $\mathrm{A}+\mathrm{Li}_{2} \mathrm{O} 10$ mass $\%$ were called Slag A5 and Slag A10, respectively.

In order to investigate an effect of slag viscosity, Slag C and $\mathrm{D}$ were prepared as shown in Table 4 and Fig. 1 . Their primary melt formation temperatures and completely melting temperatures are the same but their basicities i.e. $\mathrm{CaO} /$ $\mathrm{SiO}_{2}$ and viscosities were obviously different. ${ }^{14)}$

For consideration about an effect of molten slag formation behavior on the metal-slag separation, relationships between temperature and quantitative ratio of equilibrium phases about Slag B, C and D were derived from the ternary phase diagram as shown in Figs. 2, 3 and 4.

Melting points of slags were measured by Hot-thermocouple method. ${ }^{15)}$ In this method, a thermocouple made of Pt$30 \% \mathrm{Rh} / \mathrm{Pt}-6 \% \mathrm{Rh}$ was used as a heating filament. Through this measurement, temperature when the liquid ratio of slag reached $100 \%$ was defined as slag melting temperature.

\subsection{Experimental Procedure}

A tablet sample was put in an $\mathrm{Al}_{2} \mathrm{O}_{3}$ pan (OD: $5 \mathrm{~mm}$, ID: $4 \mathrm{~mm}$, height: $2.5 \mathrm{~mm}$ ), and then, the pan was set in the sample chamber of the infra-red image-heating furnace just under the laser microscope. An inside of the chamber was kept inert gas atmosphere by highly pure argon flow of 200 $\mathrm{ml} / \mathrm{min}$ during this experiment. The sample was heated up

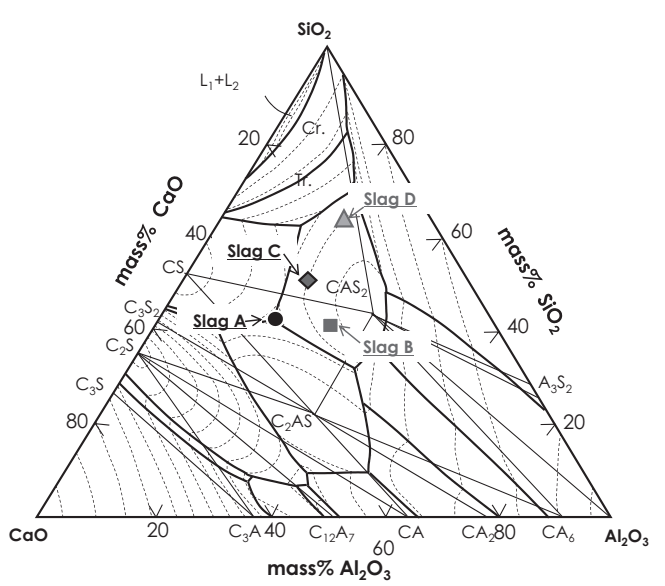

Fig. 1. Experimental slag compositions in $\mathrm{CaO}-\mathrm{SiO}_{2}-\mathrm{Al}_{2} \mathrm{O}_{3}$ ternary phase diagram. ${ }^{13)}$ 
to $1373 \mathrm{~K}$ rapidly at the heating rate of $16.6 \mathrm{~K} / \mathrm{s}(1000 \mathrm{~K} / \mathrm{min})$ to prevent from carburization at low temperature. After the sample temperature reached $1373 \mathrm{~K}$, the sample was continuously heated at $1.66 \mathrm{~K} / \mathrm{s}(100 \mathrm{~K} / \mathrm{min})$ until the shape of the tablet sample crumbled and changed to spherical shape.

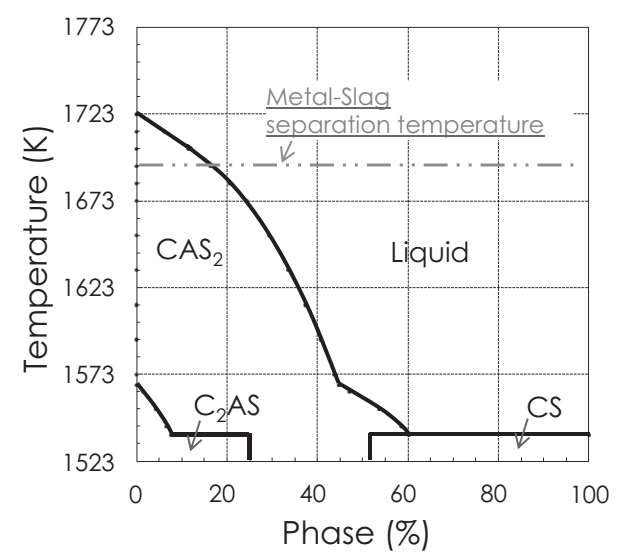

Fig. 2. Relationships between temperature and quantitative ratio of equilibrium phases about Slag B.

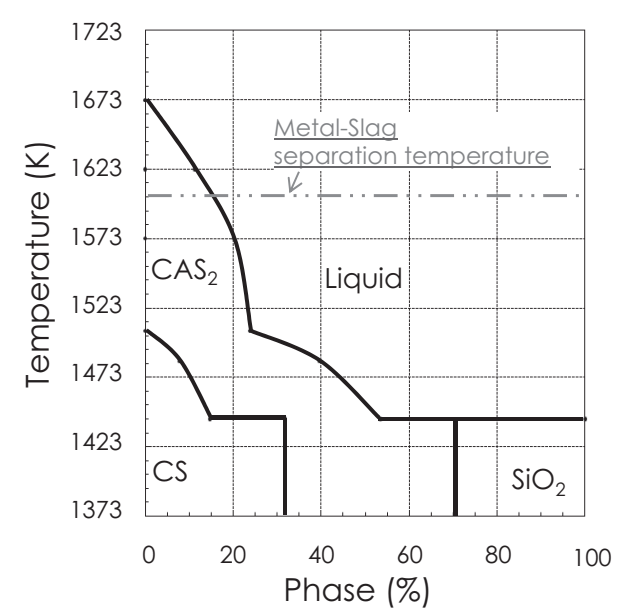

Fig. 3. Relationships between temperature and quantitative ratio of equilibrium phases about Slag C.

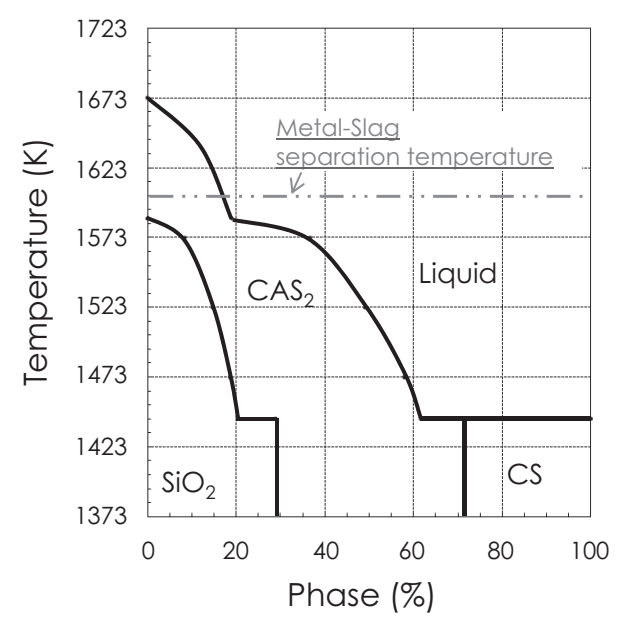

Fig. 4. Relationships between temperature and quantitative ratio of equilibrium phases about Slag D.
Then, the sample was quenched by turning off the power of the furnace. It took less than several seconds to cool the sample from the experimental temperatures to lower temperatures than $773 \mathrm{~K}$. In order to study an effect of heating rate, additional experiments were conducted with the heating rates of $0.166 \mathrm{~K} / \mathrm{s}(10 \mathrm{~K} / \mathrm{min})$ and $0.88 \mathrm{~K} / \mathrm{s}(50 \mathrm{~K} / \mathrm{min})$ after the temperature reached $1373 \mathrm{~K}$. Phenomena on the surface of the sample during this heating experiment were directly observed on a CRT monitor of the laser microscope and were recorded by a PC-based movie data collection system. The iron part of the tablet sample was cut and polished after this experiment, and an average carbon concentration in the iron part of the sample was analyzed with a wavelength dispersion type electron probe micro analyzer, EPMA, as follows. Optional 10 points in an iron part were decided and carbon concentration analyses on $270 \mu \mathrm{m}$ square zones of each point were done. From the results of these 10 zone analysis, the average carbon concentration was decided on each sample.

\section{Results}

Figures 5 and $\mathbf{6}$ show sequential photographs and illustrations obtained from "in-situ" observation of metal-slag separation behavior during the heating experiment, respectively. Firstly, change of sample's surface shape was occurred by primary melt formation of $\mathrm{Fe}-\mathrm{C}$. Secondly,
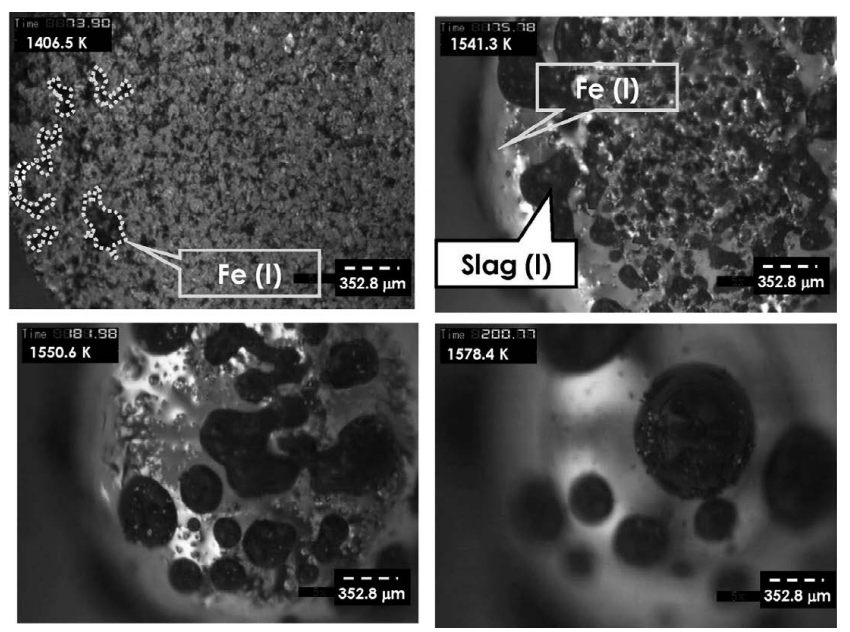

Fig. 5. Laser micrographs of sample melting behavior during heating experiment.

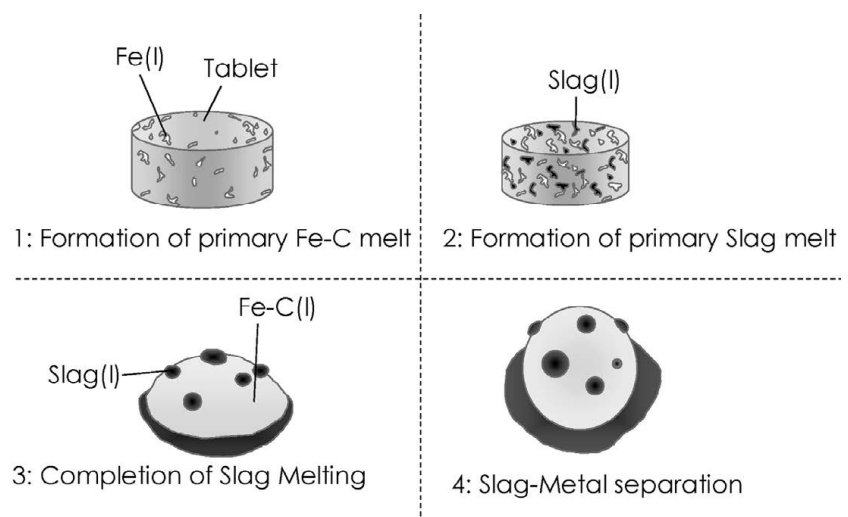

Fig. 6. Illustrations of sample melting behavior as shown in Fig. 5. 
seeping of slag primary liquid on sample's surface was found. Then, the shape of slag liquid changed into sphere with the completion of the melting of slag. Finally, metalslag separation was observed with the completion of the melting of iron. In this work, two observed behaviors, primary liquid formation of $\mathrm{Fe}-\mathrm{C}$ and metal-slag separation, were especially focused, and temperatures when they occurred were measured from this in-situ observation. The metal-slag separation temperature was determined as the temperature when the variation of the shape of the molten iron to spherical shape completely finished.

Figure 7 shows an effect of slag amount in the sample on the metal-slag separation behavior. In this figure, mixing ratio of carbon was fixed at 4 mass $\%$ and mixing slag was Slag A. From the result, temperatures of primary Fe-C liquid formation were almost the same. On the other hand, the metal-slag separation temperatures were decreased with a

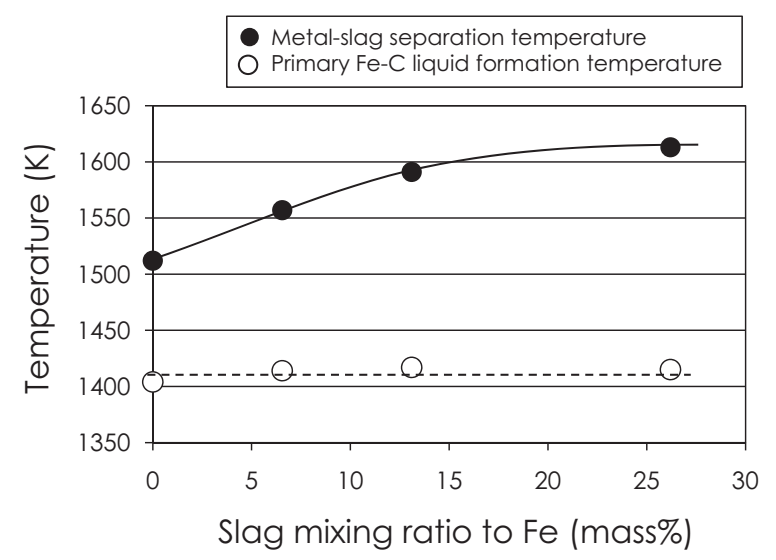

Fig. 7. Effect of slag amount in the tablet on the metal-slag separation behavior.

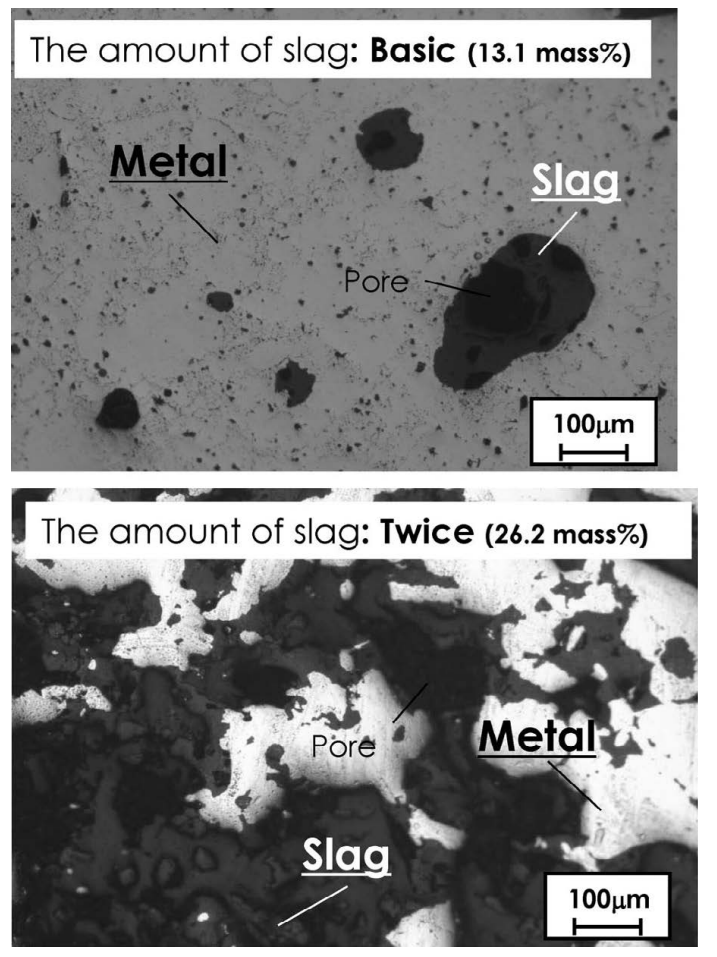

Fig. 8. Cross-section microscopic optical photos of samples after quenched from $1450 \mathrm{~K}$. decrease of slag amount in the samples. Cross-section photographs of samples after quenched from $1450 \mathrm{~K}$ are shown in Fig. 8. From this figure, it was found that twice amount of slag obviously prevented agglomeration of metal.

Figure 9 shows an effect of a decrease of slag melting temperature on the metal-slag separation behavior by the comparison of the results of Slag A with those of $\mathrm{Li}_{2} \mathrm{O}$ added samples. In this comparison, mixing ratio of carbon was fixed at 4 mass $\%$. The horizontal axis is a melting temperature of a slag and the vertical axis is an observed primary $\mathrm{Fe}-\mathrm{C}$ liquid formation temperature and slag-metal separation temperature. From this figure, temperatures of primary liquid formation were almost the same despite of the obvious difference between the slag melting temperatures. On the other hand, the metal-slag separation temperature depended on the slag melting temperature. The separation temperature decreased with a decrease of the slag melting temperature until around the eutectic temperature of $\mathrm{Fe}-\mathrm{C}$ alloy, $1426 \mathrm{~K}$. However if the slag melting temperature was lower than the eutectic temperature, the separation temperature did not depend on the slag melting behavior.

The effect of the mixing ratio of carbon to $\mathrm{Fe}$ in the samples on the metal-slag separation behaviors of Slag A, Slag B and Slag A10 are shown in Fig. 10. In this figure, each melting temperature of slag is shown as break line on the Fe-C binary phase diagram. ${ }^{16)}$ This figure also shows an effect of the slag melting temperature on the metal-slag separation behavior. The temperatures of primary $\mathrm{Fe}-\mathrm{C}$ liquid formation of all kind samples showed the same tendency, regardless of their slag compositions. It is considered that there is a strong influence of solidus line of Fe-C. Meanwhile, the metal-slag separation temperatures were affected by not only slag melting temperatures but also liquidus line temperature in $\mathrm{Fe}-\mathrm{C}$ binary phase diagram. For example, the separation temperature of Slag A containing sample decreased along the liquidus line of $\mathrm{Fe}-\mathrm{C}$ to around 1573

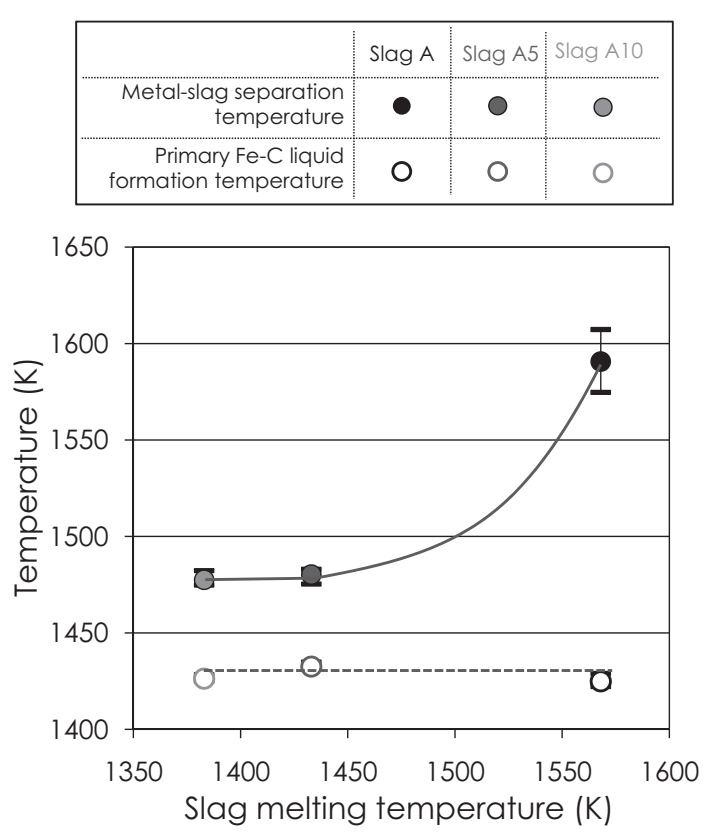

Fig. 9. Effect of slag melting temperature on the metal-slag separation behavior. Mixing ratio of carbon to Fe was fixed at 4 $\operatorname{mass} \%$. 


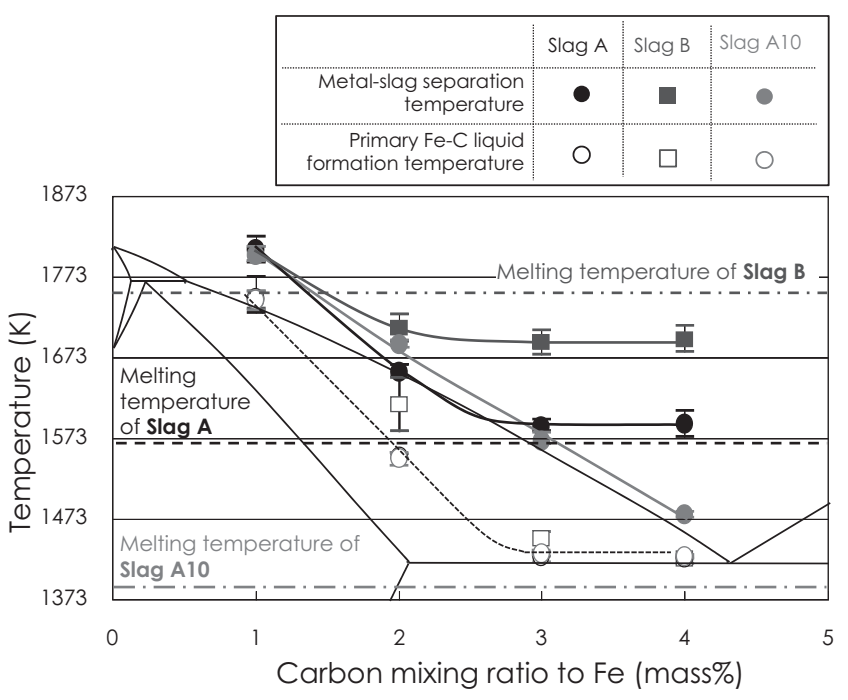

Fig. 10. Effect of slag melting temperature on Metal-slag separation behavior.

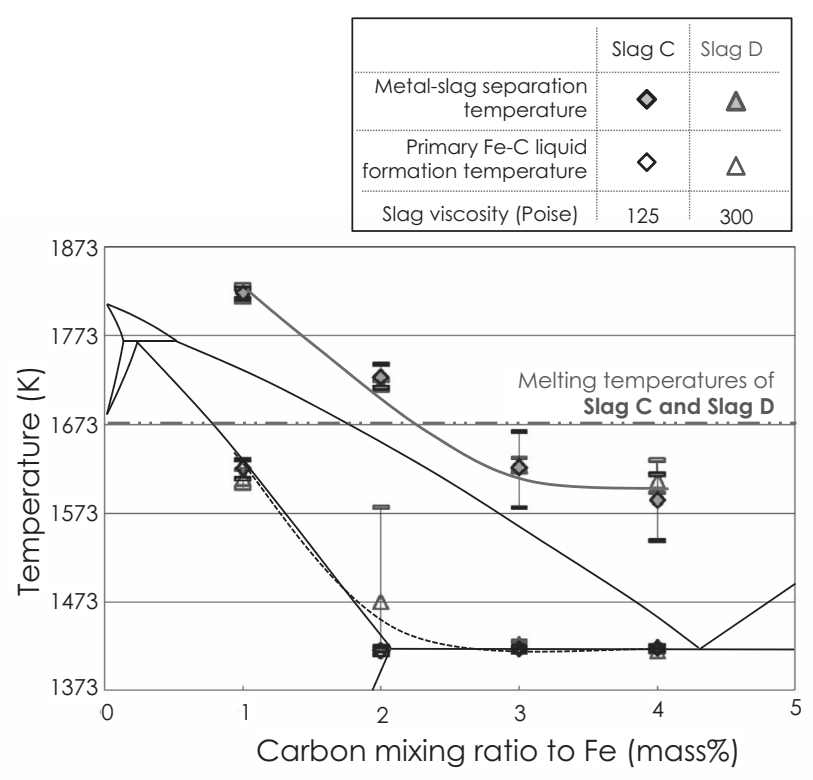

Fig. 11. Effect of difference of slag viscosity on Metal-slag separation behavior.

$\mathrm{K}$ with increasing the mixing ratio of carbon up to 3 mass $\%$. However, the metal-slag separation temperatures of 3 mass $\%$ and 4 mass $\%$ of carbon are almost the same as the melting temperature of Slag A containing sample. This result indicated that the metal-slag separation temperature was determined by the higher temperature between the slag melting temperature and the liquidus line temperature of $\mathrm{Fe}-\mathrm{C}$. This tendency was also found in case of Slag B and Slag A10.

The effect of slag viscosity on the metal-slag separation behavior is shown in Fig. 11. From this figure, it was found that both primary $\mathrm{Fe}-\mathrm{C}$ liquid formation behavior and metal-slag separation behavior showed almost the same tendency though Slag C and Slag D have obvious different viscosities. This result means it is difficult to predict the metal-slag separation behavior from only slag viscosity. At the same time, it was reconfirmed that the slag melting temperatures and liquidus line temperature of $\mathrm{Fe}-\mathrm{C}$ have strong influence
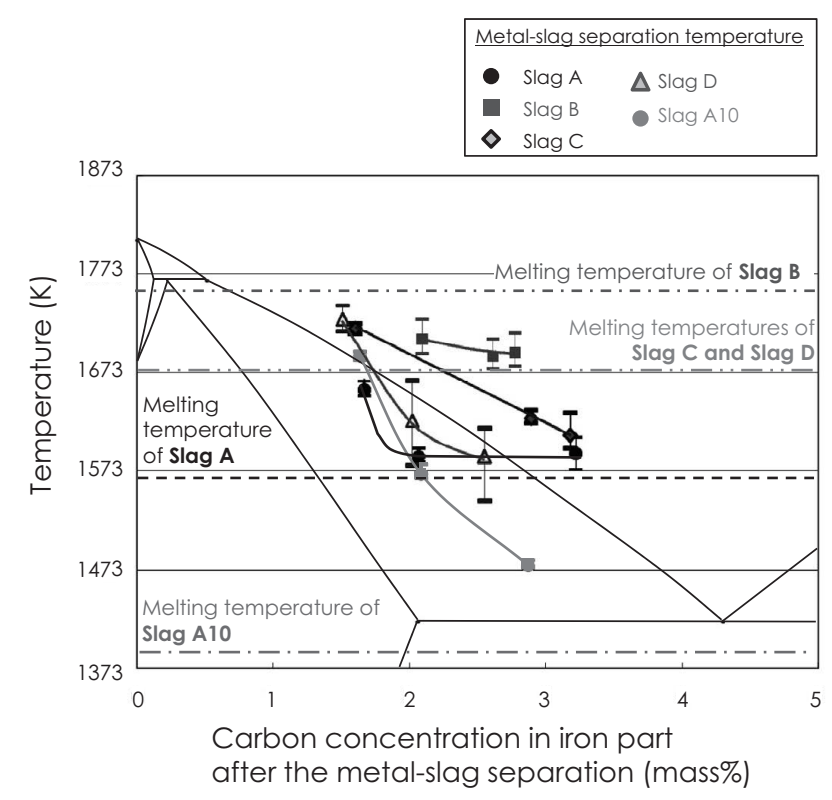

Fig. 12. Relationships between the metal-slag separation temperature and carbon concentration in iron part after the metalslag separation.

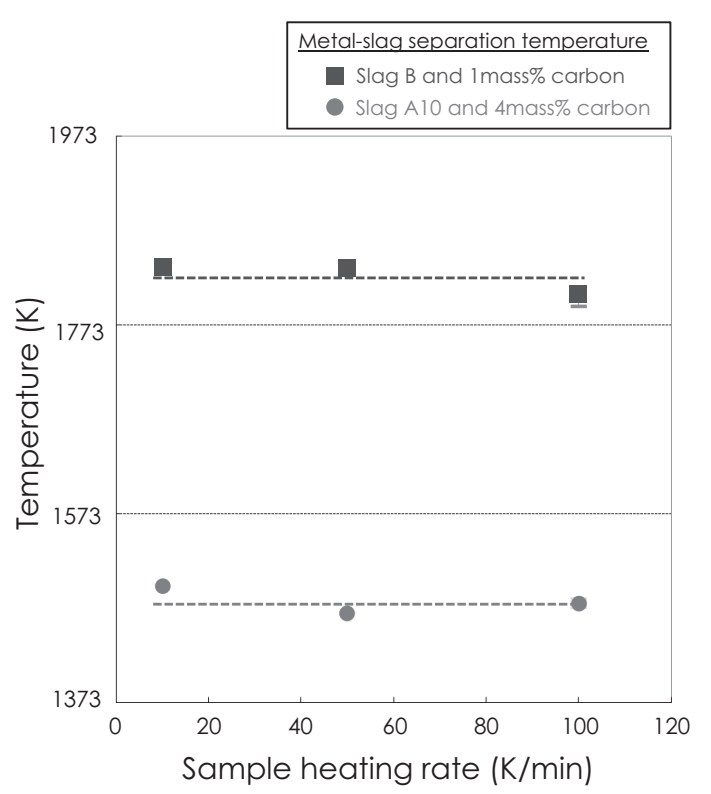

Fig. 13. Effect of sample heating rate on Metal-slag separation behavior.

on the metal-slag separation behavior.

Relationships between results of carbon concentration analysis and metal-slag separation temperatures were shown in Fig. 12. In this figure, results of 1 mass $\%$ carbon mixing samples were excluded because of measurement difficulty and accuracy problem. Carbon concentrations of after experiments were lower than the carbon mixing ratios in the experimental tablets. This result shows that all mixed carbon in the tablet was not used for carburization reaction and this fact is corresponded with a previous report. ${ }^{10)}$ It could be thought that a part of mixed carbon was pushed out from metal agglomerate during metal-slag separation. From this figure, it could be found several results of metal-slag separation temperatures were plotted lower than the liquidus line of $\mathrm{Fe}-\mathrm{C}$. It was indicated that a complete melting of iron is 
not necessary to derive the metal-slag separation behavior.

Above-mentioned experiments basically were done using the heating rate of $100 \mathrm{~K} / \mathrm{min}(1.66 \mathrm{~K} / \mathrm{s})$ after the sample temperature reached at $1373 \mathrm{~K}$. This heating rate was relatively faster than a conventional heating pattern in a blast furnace. Several comparisons between this fast heating rate and other heating rates, such as $10 \mathrm{~K} / \mathrm{min}(0.166 \mathrm{~K} / \mathrm{s})$ and $50 \mathrm{~K} / \mathrm{min}(0.88 \mathrm{~K} / \mathrm{s})$, were also carried out in this study. Figure 13 showed typical results of the comparisons. In this figure, typical two kinds of samples were used as follows. One was the easiest sample to derive the metal-slag separation because of Slag A10 and 4 mass\% carbon mixing ratio. Another needed the highest temperature to derive the metalslag separation because of Slag B and 1 mass \% carbon mixing ratio. From this figure, results of both samples showed no dependency on the heating rate. Other samples also showed almost the same tendencies in this study.

\section{Discussions}

From these experimental results, temperatures of primary $\mathrm{Fe}-\mathrm{C}$ liquid formation basically had no clear dependency on slag melting behavior though Figs. 10 and 11 were shown different trends. This difference might be derived from difference of primary liquid formation temperatures of slags ${ }^{13)}$ between 1538 K, Slag A and B, and 1443 K, Slag C and D. However, this assumption was not enough to explain the case of Slag A10. Investigation about effect of slag melting behavior on temperature of primary $\mathrm{Fe}-\mathrm{C}$ liquid formation would be carried out in the future.

Hereafter in this section, it was especially discussed about the effect of the slag melting behavior on the metal-slag separation temperatures by utilization of results from Figs. 10, 11 and 12 .

In case of Slag A10, the slag melting temperature was obviously lower than the liquidus line in $\mathrm{Fe}-\mathrm{C}$ diagram. In this case, the metal-slag separation temperature was decided by only the amount of carbon in the sample as shown in Fig. 10.

In cases of other slags, depending on the mixing ratio of carbon, the slag melting temperature was higher than liquidus line in $\mathrm{Fe}-\mathrm{C}$ diagram as shown in Figs. 10 and 11. In these cases, a meticulous comparison between the slag melting temperature and the liquidus line in $\mathrm{Fe}-\mathrm{C}$ diagram was necessary for estimation of the metal-slag separation temperature. The metal-slag separation temperature could be approximately estimated from the higher temperature between the slag melting temperature and the liquidus line of in $\mathrm{Fe}-\mathrm{C}$ diagram. This separation behavior could be explained by an ease of $\mathrm{Fe}-\mathrm{C}$ liquid agglomeration. An occurrence of the agglomeration needs a sufficient amount of $\mathrm{Fe}-\mathrm{C}$ liquid. In other words, remaining solids of $\mathrm{Fe}$ and/or slag prevent a contact between parts of $\mathrm{Fe}-\mathrm{C}$ liquid. Therefore, conditions of higher temperatures than both of the temperature of slag melting and the temperature on liquidus line of $\mathrm{Fe}-\mathrm{C}$ diagram could cause the metal-slag separation.

However, some points of experimental results have deviations to lower temperature than both lines of the temperature of slag melting and the liquidus temperature of $\mathrm{Fe}-\mathrm{C}$ in Figs. 10, 11 and 12. Results of Slags B, C and D were plotted even lower point than their slag melting points, especially at 3 and 4 mass $\%$ in carbon mixing ratio. From Figs. 2, 3 and 4 , liquid phase ratios of their slags were estimated to be around $85 \%$ at their metal-slag separation temperatures of 3 and 4 mass $\%$ carbon mixing ratio. This result indicated that the separation behavior doesn't need $100 \%$ liquid phase of slag. In other words, this amount of remaining solid slag phase could not prevent an agglomeration of $\mathrm{Fe}-\mathrm{C}$ liquid.

In Fig. 12, it was found that the metal-slag separation temperatures of some mixtures are lower than the $\mathrm{Fe}-\mathrm{C}$ liquidus line temperature. The deviation to lower temperature form the $\mathrm{Fe}-\mathrm{C}$ liquidus line was also mentioned in previous work. ${ }^{10)}$ In that work, it was concluded that agglomeration of iron molten do not need to completely melt. In other words, several remaining of solid iron in the sample could not cause prevention to change their shape the same as slag.

From these discussions, it was found that complete changes of iron and slag to liquid phases are not necessary for the metal-slag separation. It is an indispensable subject, as challenges for the future, that estimation about how much ratios of liquidus phases of iron and slag are needed to derive the metal-slag separation.

\section{Conclusions}

The effect of slag melting behavior on metal-slag separation behavior in powdery iron, slag and carbon mixture was investigated by in-situ observation method. Following results were obtained by this work.

(1) The metal-slag separation behavior was dominated largely by agglomeration behavior of liquid phase of iron.

(2) Residual solid iron phase and/or solid slag phase basically prevented the separation behavior. In other words, the separation surely occurred when both phases of iron and slag change to liquid phases. At the same time, the separation could also occur even if a small amount of solid phases still remained in the mixture.

(3) In this experimental condition, the effect of slag melting temperature on the separation was larger than the effect of slag's viscosity.

\section{REFERENCES}

1) Y. Kashiwaya, M. Kanbe and K. Ishii: ISIJ Int., 41 (2001), 818.

2) A. Kasai, M. Naito, Y. Matsui and Y. Yamagata: Tetsu-to-Hagané, 89 (2003), 1212.

3) T. Murakami and K. Nagata: Miner. Proc. Extr. Metall. Rev., 24 (2003), 253.

4) T. Matsui, Y. Hara and K. Takeda: CAMP-ISIJ, 18 (2005), 18.

5) S. Kondo and K. Ishii: Tetsu-to-Hagané, 70 (1984), A1.

6) T. Matsui, N. Ishiwata, Y. Hara and K. Takeda: ISIJ Int., 44 (2004), 2105.

7) W. Heru, K. Ohno, T. Nagasaka and M. Hino: CAMP-ISIJ, 15 (2002), 98.

8) M. W. Chapman, Brian J. Monaghan, S. A. Nightingale, J. G. Mathieson and R. J. Nightingale: ISIJ Int., 47 (2007), 973.

9) K. Ohno, T. Miki and M. Hino: ISIJ Int., 44 (2004), 2033.

10) K. Ohno, T. Miki, Y. Sasaki and M. Hino: ISIJ Int., 48 (2008), 1368.

11) K. Tsutsumi, T. Nagasaka and M. Hino: ISIJ Int., 39 (1999), 1150.

12) Y. Ueki, K. Osuga, K. Ohno, T. Maeda, K. Nishioka and M. Shimizu: Tetsu-to-Hagané, 95 (2009), 453.

13) Slag Atlas, 2nd Edition, Verlag Stahleisen GmbH, Düsseldorf, (1995), 105.

14) N. Saito, S. Sukenaga, Y. Tahori, T. Takaki and K. Nakashima: Molten Salts, chem. Technol., 47 (2004), 140.

15) Y. Ohta, K. Morinaga and T. Yanagase: Materia. Jpn., 19 (1980), 239.

16) ASM Handbook, vol. 3, Alloy Phase Diagrams, ASM International, Material Park, Ohio, (1992), 110. 